\title{
Cu-Li (Copper-Lithium)
}

\section{H. Okamoto}

The $\mathrm{Cu}-\mathrm{Li}$ phase diagram in [Massalski2] was redrawn from [1986Pel]. No intermediate phase was shown in the phase diagram.

Figure 1 shows the $\mathrm{Cu}-\mathrm{Li}$ phase diagram calculated by [2009Gas]. The existence of a new phase, $\mathrm{Cu}_{2} \mathrm{Li}_{3}$, was concluded by analyzing temperature dependence of the electromotive force for $\mathrm{Cu}-\mathrm{Li}$ alloys with various compositions.

Table 1 shows $\mathrm{Cu}-\mathrm{Li}$ crystal structure data.

\section{References}

1986Pel: A.D. Pelton, The Cu-Li (Copper-Lithium) System, Bull. Alloy Phase Diagr., 1986, 7(2), p 142-144

2009Gas: W. Gạsior, B. Onderka, Z. Moser, A. Dębski, and T. Gancarz, Thermodynamic Evaluation of $\mathrm{Cu}-\mathrm{Li}$ Phase Diagram from EMF Measurements and DTA Study, Calphad 2009, 33, p 215-220

Table 1 Cu-Li crystal structure data

\begin{tabular}{lccccc}
\hline Phase & Composition, at.\% Li & Pearson symbol & Space group & Strukturbericht designation & Prototype \\
\hline$(\mathrm{Cu})$ & $0-18.3$ & $c F 4$ & $F m \overline{3} m$ & $\ldots 1$ & \\
$\mathrm{Cu}_{2} \mathrm{Li}_{3}$ & 60 & $\ldots$ & $\ldots$ & $\ldots$ & $\mathrm{Cu}$ \\
$(\beta \mathrm{Li})$ & 100 & $c / 2$ & $I m \overline{3} m$ & $A 2$ & $\mathrm{~W}$ \\
\hline
\end{tabular}

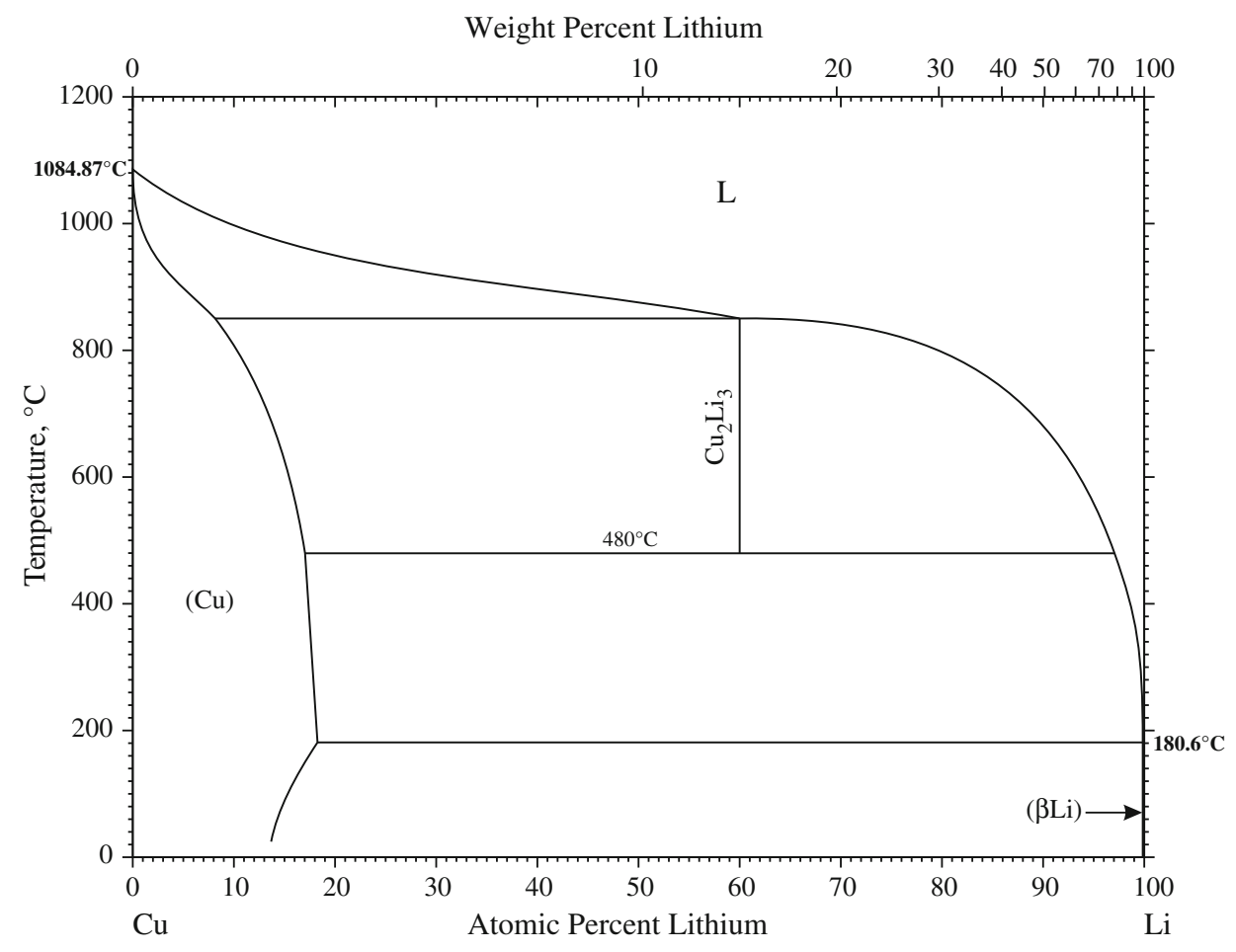

Fig. $1 \mathrm{Cu}$-Li phase diagram 